\title{
HLA and Disease Associations in Koreans
}

\author{
Stephen Ahn ${ }^{1}$, Hee-Back $\mathrm{Choi}^{2}$ and Tai-Gyu Kim ${ }^{1,2} *$ \\ ${ }^{1}$ Department of Microbiology and Immunology, ${ }^{2}$ Catholic Hematopoietic Stem Cell Bank, College of Medicine, The Catholic University \\ of Korea, Seoul 137-701, Korea
}

The human leukocyte antigen ( $H L A)$, the major histocompatibility complex (MHC) in humans has been known to reside on chromosome 6 and encodes cell-surface antigen-presenting proteins and many other proteins related to immune system function. The HLA is highly polymorphic and the most genetically variable coding loci in humans. In addition to a critical role in transplantation medicine, HLA and disease associations have been widely studied across the populations worldwide and are found to be important in prediction of disease susceptibility, resistance and of evolutionary maintenance of genetic diversity. Because recently developed molecular based HLA typing has several advantages like improved specimen stability and increased resolution of HLA types, the association between HLA alleles and a given disease could be more accurately quantified. Here, in this review, we have collected HLA association data on some autoimmune diseases, infectious diseases, cancers, drug responsiveness and other diseases with unknown etiology in Koreans and attempt to summarize some remarkable HLA alleles related with specific diseases.

[Immune Network 2011;11(6):324-335]

\section{INTRODUCTION}

For more than 30 years since the first report on the association of a disease with a specific HLA (human leukocyte antigen) gene, such association studies have been performed for more than 500 different diseases (1). One of reasons to study gene association is to define disease-specific susceptibility and protective markers for immunogenetic profiling, risk assessment and therapeutic decisions (2). Although not all in- dividuals with susceptibility alleles will develop the disease and not all disease individuals have the high risk alleles, most diseases showing HLA association suggested the pathogenesis related with immune system and majority of them are regarded as autoimmune diseases (3). Diseases with a strong association with certain specific HLA class I or class II genes include type 1 diabetes, rheumatoid arthritis, ankylosing spondylitis, and allergic diseases. Recently, infectious diseases, cancers and drug-induced adverse effects are also associated with increased susceptibility with HLA.

The understanding on MHC restriction of cellular immune response provided to speculate the evolutionary maintenance of the genetic diversity of HLA types, presumably through the ability to present more peptide epitopes to $\mathrm{T}$ lymphocytes. Particular HLA types might present more peptide epitopes for a given virus. Heterozygous HLA might have more chance to protection than homozygous. The diseases associated with HLA class I alleles may involve cytotoxic $\mathrm{T}$ lymphocytes whereas those associated with HLA class II may involve $\mathrm{T}$ helper or suppressor lymphocytes. Studies of polymorphic microsatellite markers have suggested the other HLA-linked genes influencing disease susceptibility and/or resistance within HLA region. HLA-linked genes such as LMP (low molecular weight proteasome), TAP (transporter associated with antigen processing), HLA-DM (non-classical class II product) and TNF (tumor necrosis factor) are also likely to be under the influence of linkage disequilibrium with the classical HLA genes (4).

Different populations tend to show different distributions of alleles and extended haplotypes. Concordant results between studies of different ethnic groups increase the possi-

Received on October 1, 2011. Revised on October 13, 2011. Accepted on October 19, 2011.

(C) This is an open access article distributed under the terms of the Creative Commons Attribution Non-Commercial License (http://creativecommons.org/licenses/by-nc/3.0) which permits unrestricted non-commercial use, distribution, and reproduction in any medium, provided the original work is properly cited.

*Corresponding Author. Tel: 82-2-2258-7341; Fax: 82-2-3476-7355; E-mail: kimtg@catholic.ac.kr

Keywords: HLA, Disease association, Korean 
bility of HLA association, whereas discordant result may mean that the associated HLA allele is weakly associated with a particular disease and that the different ethnic groups don't have proper distribution of HLA alleles to demonstrate disease susceptibility (5). A population analysis and comparison among different racial and ethnic groups are needed to make these genetic interactions more informative (6).

In this review, we have summarized reports on HLA and disease association in Koreans, which were searched from PubMed and KoreaMed with the keywords HLA, associations and Korea (or Korean, or Koreans) among papers published from 1990 to 2011 September.

\section{RHEUMATOLOGIC DISEASES (Table I)}

\section{Rheumatoid Arthritis (RA)}

RA is a condition in which complex inflammation occurs

Table I. Rheumatologic diseases positively associated with HLA alleles in Korean population

\begin{tabular}{|c|c|c|c|}
\hline Disease & $\begin{array}{l}\text { Odds } \\
\text { ratio }\end{array}$ & p-value & Ref. \\
\hline \multicolumn{4}{|l|}{ Rheumatoid arthritis (RA) } \\
\hline DRB1*0401 & 8.8 & $<0.05$ & (8) \\
\hline DRB $1 * 0405$ & 5.88 & $<0.001$ & (9) \\
\hline DRB1*0405 & 9.4 & $<0.00005$ & (8) \\
\hline DRB $1 * 0405$ & 6.6 & $<10^{\wedge}-6$ & (7) \\
\hline DQA $1 * 03$ & 5.2 & $<10^{\wedge}-6$ & (7) \\
\hline $\mathrm{DQB} 1 * 04$ & 3.5 & $<0.002$ & (7) \\
\hline $\begin{array}{r}\text { DRB } 1 * 0405-D Q A 1 * 03- \\
\text { DQCAR113-DQB1*03 }\end{array}$ & 17.7 & $<0.002$ & (7) \\
\hline \multicolumn{4}{|c|}{ Systemic lupus erythematosus (SLE) } \\
\hline DR9 & $>1$ & $<0.05$ & (11) \\
\hline $\mathrm{DRB} 1 * 15$ & 1.7 & $<0.02$ & (10) \\
\hline DRB1*1501 & $>1$ & $<0.05$ & (11) \\
\hline \multicolumn{4}{|l|}{ Ankylosing spondylitis (AS) } \\
\hline B27 & $96.3 \%$ & $<0.0001$ & $(12)$ \\
\hline$B * 2705$ & $92.2 \%$ & & $(12)$ \\
\hline \multicolumn{4}{|c|}{ Adult onset Still's disease (AOSD) } \\
\hline $\mathrm{DRB} 1 * 12$ & 2.27 & 0.028 & (13) \\
\hline $\mathrm{DRB} 1 * 15$ & 2.16 & 0.013 & (13) \\
\hline \multicolumn{4}{|l|}{ Systemic sclerosis (SSc) } \\
\hline $\mathrm{DRB} 1 * 1502$ & 6.3 & 0.0001 & $(14)$ \\
\hline $\mathrm{DPB} 1 * 0901$ & 3.21 & $2.55^{*} 10^{\wedge}-5$ & $(15)$ \\
\hline DPB $1 * 1301$ & 3.04 & $7.61 * 10^{\wedge}-8$ & $(15)$ \\
\hline \multicolumn{4}{|l|}{ Behcet's disease (BD) } \\
\hline HLA-B51 & 1.87 & 0.022 & $(16)$ \\
\hline
\end{tabular}

within the joint causing erosion and destruction of articular components. RA is a polygenic disease with both environmental and genetic factors which, when combined, result in the disease process and its clinical outcome. It has been suggested that RA is associated with genes which lie within the HLA complex. This region contains many genes that encode proteins, which play an important role in the initiation and regulation of immune response. In initial reports of an association of DRB1*04 with RA, certain DR and DQ alleles have proved to interact with RA. These reports suggested that the DR/DQ region might be more important than any other part of the HLA region in terms of defining the development of the mechanisms of RA. In Korean population, the frequency of DR4 in RA patients was significantly greater than that in controls and DR6 was decreased. HLA-DRB1*0401, DRB1*0405, DQA1*03, DQB1*04 was positively associated with RA (7-9). Haplotype DRB1* 0405-DQA1*03-DQCAR113-DQB1*03 haplotype showed highest relative risk value (7).

\section{Systemic Lupus Erythematosus (SLE)}

SLE is an autoimmune disease characterized by immune dysregulation, leading to high levels of autoantibody production, immune complex deposition and tissue injury. HLA genes have received significant attention in human SLE, and there is evidence supporting a role for specific extended HLA haplotypes as genetic risk factors for disease expression in several populations. HLA-DR2 and DR9 have shown consistent associations with SLE in European Caucasian populations (10). In Koreans, DR9 and DRB1*1501 showed positive association with SLE $(10,11)$.

\section{Ankylosing Spondylitis (AS)}

AS is a chronic inflammatory disease of the axial skeleton with variable involvement of peripheral joints and nonarticular structures. HLA-B27 is strongly associated with AS and its subtypes differ in their ethnic distribution. Studies worldwide have shown that $B^{*} 2701, B^{*} 2702, B * 2704, B * 2705$, $B^{*} 2707, B^{*} 2708, B^{*} 2714, B^{*} 2715$, and $B * 2719$ are AS-predisposing subtypes (12). In Koreans, a study showed that B27 (96.3\%) is strongly associated with AS and the major subtype of B27 in patients with AS is B*2705 (92.2\%) (12).

\section{Adult Onset Still's Disease (AOSD)}

AOSD is a rare form of inflammatory arthritis that was characterized by Bywaters EG in 1971 and the underlying cause is unknown. Some studies have suggested that Korean AOSD patients have distinct immunogenetic profiles. It would be valuable to assess the relationships between HLA-DRB1 genes and polymorphisms of proinflammatory cytokines to define 
the pathogenesis of AOSD. In Korean population, patients with AOSD had more frequent DRB1*12 and DRB1*15 and less frequent DRB1*04 compared to controls (13).

\section{Systemic Sclerosis (SSc)}

SSc is a multisystem connective tissue disease of unknown etiology that is thought to have an autoimmune origin. Recent investigations on the immunogenetic background of the disease have shown that HLA class II alleles are associated with the disease. SSc patients with anti-topo I have been shown to have distinct associations with HLA-DR or DQ alleles. HLA-DRB1*1104 in Caucasians and DRB1*1502 in Japanese were found to be associated with anti-topo I positive SSc. In Korean population, two studies showed that DRB1*1502, DPB1*0901 and DPB1*1301 were significantly associated with SSc $(14,15)$.

\section{Behcet's Disease (BD)}

$\mathrm{BD}$ is $\mathrm{s}$ a rare immune-mediated systemic vasculitis that often presents with mucous membrane ulceration and ocular involvements. The HLA-B51 allele is known to be associated with BD in many ethnic groups. However, it has not yet been clarified whether the B51 gene itself is the pathogenic gene related to $\mathrm{BD}$ or whether it is some other gene in linkage disequlibrium with B51. A study aimed to investigate the association of B51 with BD showed the prevalence of B51 was significantly increased in Korean patients with BD (16).

\section{ENDOCRINE DISEASES (Table II)}

\section{Autoimmue Thyroid Disease (AITD)}

AITD are organ-specific autoimmune disorders caused by thyroid autoantibodies, which result in thyroid dysfunction. The mechanism underlying the pathogenesis is unclear, but AITD may occur when genetically susceptible individuals are exposed to environmental modulating triggers such as infection, iodine, and stress. Tissue infiltration of the thyroid gland by thyroid autoantibodies that mediate humoral immune reactions causes hyperthyroidism in Graves' disease (GD) and hypothyroidism in Hashimoto's disease (HD). The fact that GD and HD are observed commonly in the same family tree may reflect a similar genetic basis between the two diseases.

The HLA alleles associated with GD are reported to be variable in different ethnic groups. In Caucasian, HLA-B8, DR3 by serotyping and DRB1*0301, DRB3*0101, DQA1*0501, DQB1*0201 by genotyping were associated with genetic susceptibility to GD. Also, Many Japanese studies showed that HLA-A2, B35, B46, Cw11, DR5, DR8 by serotyping and HLA-
DPB1*0501, DRB1*0803, DRB1*1403, DQA1*0103 by genotyping were associated with GD. In Hong Kong Chinese, HLAB46, DR9, and DQB1*0303 were found to be associated with GD. Recently, HLA-B46, DR2, DR9, DR53, DQw1, and DRB1*0901 were related to GD in Singapore and Taiwan, respectively $(17,18)$.

Early onset AITD had more frequent HLA-B46 and $\mathrm{Cw}^{*} 01$ in Koreans (17). DRB1*030101, DRB1*080201, DRB1*0803, DRB1*140301 and DRB1*1602 were associated with GD and DRB1*0803-DQB1*0601 and DRB1*1602-DQB1*0502 haplotypes were also associated with GD $(18,19)$. Also, The frequency of DR8 and DQB1*0302 was increased in patients with thyrotropin receptor-blocking antibody-positive atrophic autoimmune thyroiditis (20).

\section{Insulin-dependent Diabetes Mellitus (IDDM)}

IDDM is an autoimmune disease resulting from the selective destruction of insulin-producing islet cells in the pancreas. The precise etiology of IDDM is not well understood. Recent gene mapping studies have indicated that a large number of genes contribute to the genetic susceptibility to IDDM and the

Table II. Endocrine diseases positively associated with HLA alleles in Korean population

\begin{tabular}{|c|c|c|c|}
\hline Disease & $\begin{array}{l}\text { Odds } \\
\text { ratio }\end{array}$ & p-value & Ref. \\
\hline \multicolumn{4}{|c|}{ Autoimmue thyroid disease (AITD) } \\
\hline B46 & 5.46 & $<2.4 * 10^{-8}$ & (17) \\
\hline $\mathrm{CW}^{*} 01$ & 2.20 & $<0.00016$ & (17) \\
\hline \multicolumn{4}{|l|}{ Graves' disease (GD) } \\
\hline $\mathrm{DRB} 1 * 030101$ & 2.88 & 0.03 & (18) \\
\hline DRB1 $* 080201$ & 2.41 & 0.05 & (18) \\
\hline $\mathrm{DRB} 1 * 0803$ & 2.27 & 0.03 & (19) \\
\hline DRB1*140301 & 3.47 & 0.04 & (18) \\
\hline DRB $1 * 1602$ & 22.34 & 0.03 & (19) \\
\hline DRB1*0803-DQB1*0601 & 2.45 & 0.001 & (19) \\
\hline DRB1*1602-DQB1*0502 & 22.34 & 0.0002 & (19) \\
\hline \multicolumn{4}{|c|}{$\begin{array}{l}\text { Thyrotropin Receptor-blocking antibody-positive } \\
\text { atrophic autoimmune thyroiditis }\end{array}$} \\
\hline DR8 & 5.7 & 0.003 & (20) \\
\hline $\mathrm{DQB} 1 * 0302$ & 4.4 & 0.012 & (20) \\
\hline \multicolumn{4}{|c|}{ Insulin-dependent diabetes mellitus (IDDM) } \\
\hline $\mathrm{DRB} 1 * 0301$ & 6.1 & $<0.00001$ & (22) \\
\hline DRB $1 * 0407$ & 14.1 & 0.006 & (22) \\
\hline DRB1*0901 & 1.6 & 0.05 & $(22)$ \\
\hline DQB $1 * 0201$ & 2.4 & 0.0006 & (22) \\
\hline DRB1*0401-DQB*0302 & 6.5 & 0.03 & $(22)$ \\
\hline DRB1*0405-DQB*0302 & 14.6 & 0.002 & $(22)$ \\
\hline
\end{tabular}


HLA class II region encodes the most important genetic factors in IDDM. In most Caucasian populations, the HLA region may explain a large proportion, but less than $50 \%$, of the total familial aggregation of the disease. The HLA-DRB1*0405-DQA1* 0302-DQB1*0401 haplotype is known to be the main susceptible haplotype in Japanese IDDM. The most common allele DQCAR 113 and HLA-DRB1*0405-DQA1*0302-DQCAR113DQB1*0401 haplotype were increased in Japanese IDDM patients compared with normal controls (21).

In Korean population, the frequencies of HLA-DRB1*0301, DRB1*0407, DRB1*0901 and DQB1*0201 were significantly increased in IDDM patients and DRB1*0401-DQB*0302 and DRB1*0405-DQB1*0302 haplotypes were significantly associated with IDDM (22).

\section{DERMATOLOGIC \& ALLERGIC DISEASES (Table III)}

\section{Psoriasis}

Psoriatic lesions are characterized by epidermal hyperplasia and the presence of acute and chronic inflammatory cells, Activated lymphocytes, other immune accessory cells and lymphokines have also been detected in psoriatic plaques. Epidemiologic studies, including concordance rates in twin pairs and siblings suggest that genetic factors are strongly involved in the pathogenesis of the disease. Psoriasis has been reported to be significantly associated with the HLA-A1, A2, A30, B13, B17, B37, B39, B46, Cw6, Cw7, Cw9, Cw11, DR7, and DQA1*0201 (23). This relationship, however, tends to vary between patients of different racial and ethnic backgrounds. In Koreans, $\mathrm{CW}^{*} 0602$ showed the strongest association with psoriasis. The frequencies of $\mathrm{A} 1, \mathrm{~A} 30, \mathrm{~B} 13, \mathrm{~B} 37, \mathrm{DRB1} 07$, DRB1*10, DQA1*02, DQB1*02 and DPB1*1701 were significantly increased in patients with psoriasis (23). A1-B37-Cw* 0602-DRB1*10-DQA1*01-DQB1*05, A30-B13-Cw*0602-DRB1*07DQA1*02-DQB1*02, and A30-B13-Cw*0602-DRB1*07-DQA1*02DQB1*02-DPB1*1701 haplotypes showed significant association with psoriasis (23).

\section{Atopic Dermatitis}

Atopic dermatitis is an inflammatory, chronically relapsing, non-contagious and pruritic skin disorder and has been seen to result from multifactorial inheritance, with interaction between genetic and environmental factors. But, the genetic association may differ according to the ethnic backgrounds. In Koreans, a study showed the frequency of HLA-A24 was significantly increased in patients with atopic dermatitis compared to controls (24).
Table III. Allergic \& dermatologic diseases positively associated with HLA alleles in Korean population

\begin{tabular}{|c|c|c|c|}
\hline Disease & $\begin{array}{l}\text { Odds } \\
\text { ratio }\end{array}$ & p-value & Ref. \\
\hline \multicolumn{4}{|l|}{ Psoriasis } \\
\hline A1 & 17.0 & $<9 * 10^{-7}$ & (23) \\
\hline A30 & 5.5 & $<2 * 10^{-5}$ & (23) \\
\hline B13 & 5.6 & $<4 * 10^{-6}$ & (23) \\
\hline B37 & 30.3 & $<7 * 10^{-7}$ & (23) \\
\hline $\mathrm{Cw}^{*} 0602$ & 36.0 & $<10^{-8}$ & (23) \\
\hline $\mathrm{DRB} 1 * 07$ & 5.9 & $<2 * 10^{-6}$ & (23) \\
\hline DRB $1 * 10$ & 26.4 & $<4 * 10^{-6}$ & (23) \\
\hline DQA $1 * 02$ & 6.2 & $<5^{*} 10^{-7}$ & (23) \\
\hline DQB1*02 & 2.5 & $<0.005$ & (23) \\
\hline $\mathrm{DPB} 1 * 1701$ & 24.6 & $<9 * 10^{-6}$ & (23) \\
\hline $\begin{array}{l}\text { A1-B37-Cw*0602-DRB } 1 * 10- \\
\text { DQA } 1 * 01-D Q B 1 * 05\end{array}$ & 17.7 & $<3 * 10^{-4}$ & (23) \\
\hline $\begin{array}{l}\text { A30-B13-Cw*0602-DRB } 1 * 07- \\
\text { DQA } 1 * 02-\mathrm{DQB} 1 * 02 \\
\text { (particularly early age in female) }\end{array}$ & 19.2 & $<2 * 10^{-7}$ & $(23)$ \\
\hline $\begin{array}{l}\text { A30-B13-Cw*0602-DRB1*07 } \\
\text {-DQA } 1 * 02-D Q B 1 * 02-D P B 1 * 1701\end{array}$ & 21.0 & $<5^{*} 10^{-5}$ & $(23)$ \\
\hline \multicolumn{4}{|l|}{ Atopic dermatitis } \\
\hline A24 & 2.14 & $<0.05$ & (24) \\
\hline \multicolumn{4}{|c|}{ Specific IgE responses to $D$. pteronyssinus } \\
\hline $\mathrm{DRB} 1 * 07$ & 5.93 & 0.02 & $(25)$ \\
\hline $\mathrm{DRB} 1 * 07$ & 4.43 & 0.009 & (26) \\
\hline \multicolumn{4}{|l|}{ Asthma } \\
\hline DPB $1 * 0301(* \mathrm{AlA})$ & 6.3 & $<0.001$ & (27) \\
\hline $\begin{array}{l}\text { DRB } 1 * 1501-\mathrm{DQB} 1 * 0602- \\
\text { DPB } 1 * 0501(* * \text { TDI-OA) }\end{array}$ & 7.24 & $<0.001$ & (28) \\
\hline
\end{tabular}

*AIA: aspirin-intolerant asthma, ${ }^{* *} \mathrm{TDI}-\mathrm{OA}$ : toluene diisocyanateinduced occupational asthma.

\section{Specific lgE Responses to House Dust Mite (D. pteronys- sinus)}

The allergic reaction occurs when the immune system misinterprets a usually innocuous substance as a disease agent and produces a type of antibody against it, called immunoglobulin E (IgE). House dust mites are a common cause of asthma and allergic symptoms worldwide. So, IgE responses to house dust mite-derived allergens seem to be the most important in the development of atopic asthma and rhinitis, but it has been difficult to demonstrate genetic control of the IgE response to the allergens. In this backgrounds, two studies showed that HLA-DRB1*07 was significantly higher in subjects with high serum-specific IgE response to crude house dust mite allergens than the controls $(25,26)$. 


\section{Asthma}

Aspirin (ASA)-intolerant asthma (AIA) affecting 10\% to 20\% of adults with asthma is characterized by ASA hypersensitivity, bronchial asthma, and chronic rhino sinusitis with nasal polyposis. Although the pathogenic mechanism is not fully understood, a possible involvement of immunologic mechanisms in association with HLA alleles, particularly HLADPB1*0401 and DPB1*0301 was suggested in a white population with AIA. However, these data have focused on whites and are required to be confirmed in other ethnic populations. In Korean population, the frequency of DPB1* 0301 was significantly increased in AIA patients (27). There was other type of asthma, toluene diisocyanate (TDI)-induced occupational asthma (TDI-OA). The TDI-OA is incompletely understood and several studies have suggested immunologic mechanisms, including specific IgE responses. A few studies have suggested HLA associations with TDI-induced asthma in Western countries. The first investigation of associations between HLA class I and II alleles and TDI-induced asthma patients in Korean population was performed. The DRB1*1501DQB1*0602-DPB1*0501 haplotype was significantly higher in TDI-OA patients than in unexposed normal controls (28).

\section{INFECTIOUS DISEASES AND CANCERS (Table IV)}

\section{Hepatitis B Virus (HBV) Infection}

Chronic hepatitis $B$ infection is the leading cause of cirrhosis and hepatocellular carcinoma. Some studies have suggested that HLA may be involved in the chronicity of HBV infection. In Korean population, hepatitis B chronicity was positively associated with HLA-A33 and -DR7. The significant haplotypes were A33-DR7, B44-DR7 and A33-B44-DR7 in Koreans (29). HBV-Glomerulonephritis (GN)

$\mathrm{HBV}-\mathrm{GN}$ is occurring at high prevalence in most Asian endemic areas. There have been some reports on HLA associations with HBV infections; however, HLA association with HBV-GN has been rarely reported. In these backgrounds, some results were presented that a strong association with HLA-DR2 and DQB1*0601 was observed in HBV-GN patients, compared with $\mathrm{HBsAg}(-)$ controls. Different DR2 alleles were associated with different pathologic subtypes of HBV-GN: DRB1*1501 with membranous nephropathy (MN) and DRB1*1502 with membranoproliferative glomerulonephritis (MPGN) (30).

\section{Hepatitis C Virus (HCV) Infection}

Hepatitis $\mathrm{C}$ is an infectious disease primarily affecting the liv- er, caused by the HCV. The infection is often asymptomatic, but chronic infection can lead to scarring of the liver and ultimately to cirrhosis, which is generally apparent after many years. Recent data have shown that the clinical outcome of HCV infection may be influenced by the host genetic factor, especially HLA. In Koreans, the frequencies of HLA-A3, B35 and B46 were significantly increased in chronic HCV carriers compared with the controls (31). The DRB1*0803-DQB1*0601 haplotype was positively associated and DQA1*0501-DQB1*0201 was negatively associated with chronic HCV carrier (31).

Table IV. Infectious disease and cancers positively associated with HLA alleles in Korean population

\begin{tabular}{|c|c|c|c|}
\hline Disease & $\begin{array}{l}\text { Odds } \\
\text { ratio }\end{array}$ & p-value & Ref. \\
\hline \multicolumn{4}{|l|}{ Hepatitis B chronicity } \\
\hline A33 & 1.59 & $<0.004$ & (29) \\
\hline DR7 & 2.58 & $<0.001$ & (29) \\
\hline A33 and DR7 & 3.63 & $<0.001$ & (29) \\
\hline A33-DR7 & 4.47 & $<0.001$ & (29) \\
\hline B44-DR7 & 5.44 & $<0.001$ & (29) \\
\hline A33-B44-DR7 & 7.31 & $<0.001$ & (29) \\
\hline \multicolumn{4}{|l|}{ HBV-glomerulonephritis (GN) } \\
\hline DR2 & 4.0 & 0.0002 & (30) \\
\hline DQB $1 * 0601$ & 3.2 & 0.007 & (30) \\
\hline $\mathrm{DRB} 1 * 1501(* \mathrm{MN})$ & 3.8 & $<0.05$ & (30) \\
\hline DRB1*1502 $(* *$ MPGN $)$ & 14.5 & 0.003 & (30) \\
\hline \multicolumn{4}{|c|}{ Chronic hepatitis C virus (HCV) infection } \\
\hline A3 & 3.5 & $<0.04$ & $(31)$ \\
\hline B35 & 2.0 & $<0.03$ & (31) \\
\hline B46 & 2.5 & $<0.02$ & (31) \\
\hline DRB1*0803-DQB1*0601 & 2.5 & $<0.02$ & (31) \\
\hline \multicolumn{4}{|l|}{ Pulmonary tuberculosis } \\
\hline DRB $1 * 0803$ & 1.97 & 0.012 & $(32)$ \\
\hline $\begin{array}{l}\text { DRB } 1 * 0803 \text { (drug resistance and } \\
\text { more lung lesion) }\end{array}$ & 2.50 & 0.022 & $(32)$ \\
\hline DQB1*0601 & 2.07 & 0.005 & $(32)$ \\
\hline \multicolumn{4}{|c|}{ Nontuberculous mycobacterial lung disease } \\
\hline $\mathrm{DRB} 1 * 11$ & 1.91 & 0.045 & (33) \\
\hline \multicolumn{4}{|l|}{ Gastric carcinoma } \\
\hline DRB $1 * 0404$ & 29.64 & 0.0067 & $(34)$ \\
\hline \multicolumn{4}{|l|}{ Non-hodgkin's lymphoma } \\
\hline B51 & 1.86 & $<0.05$ & (35) \\
\hline DRB1*09 & 2.7 & $<0.0006$ & (35) \\
\hline DQB $1 * 03$ & 2.3 & $<0.002$ & (35) \\
\hline B51-DRB1*09-DQB1*03 & 3.61 & $<0.04$ & (35) \\
\hline
\end{tabular}

${ }^{*} \mathrm{MN}$ : membranous nephropathy, ${ }^{* *} \mathrm{MPGN}$ : membranoproliferative glomerulonephritis. 


\section{Pulmonary Tuberculosis}

It is estimated that approximately one third of the world's population is infected with Mycobacterium tuberculosis. An interesting feature of mycobacterial infection is that only $10 \%$ of persons infected with Mycobacterium tuberculosis develop clinical tuberculosis (TB), indicating the existence of host genetic factors regulating disease expression. As one of the host genetic factors, associations of HLA with susceptibility to TB have been studied in many ethnic groups. In Korean population, the frequencies of DRB1*0803 and DQB1*0601 were significantly increased in TB patients (32). These alleles were associated with disease progression of $\mathrm{TB}$, exerting influence on the development of drug resistance, severe disease, and recurrent disease (32).

\section{Nontuberculous Mycobacterial Lung Disease}

The incidence of pulmonary disease caused by nontuberculous mycobacteria (NTM) in human immunodeficiency virus (HIV)- negative patients is increasing worldwide. NTM are ubiquitous environmental organisms. As exposure to these organisms is universal and the occurrence of the disease is rare, normal host-defense mechanisms in most cases appear to be sufficiently effective in preventing infection. Previous studies have revealed that NTM lung disease is associated with specific HLA alleles in the Japanese population. And a recent study showed patients with NTM lung disease showed an increased frequency of HLA-DRB1*11 in Korean population (33).

\section{Gastric Carcinoma}

Gastric carcinogenesis is a multi-step process and is influenced by several etiological agents, including the host's genetic factors. Since whether a patient remains with chronic superficial gastritis (CSG) or progresses to either chronic atrophic gastritis (CAG) or gastric carcinoma (GC) could be a genetic predisposition unique in each population, HLA alleles could be discriminative in predicting the risk of CSG progression to precancerous CAG and GC in Koreans. In a study aimed to investigate the association of HLA class II allele with GC progression, GC was very strongly associated with HLA-DRB1*0404 in Korean population (34).

\section{Non-Hodgkin's Lymphoma (NHL)}

Lymphoid malignancies are neoplasms that arise from B or $\mathrm{T}$ cells that are at various stages of normal lymphocyte development. The MHC has been extensively studied and many of its associations with HLA been reported. Hodgkin's disease was the first disease defined to be associated with HLA system. But, these studies have shown different results, according to the ethnicity. In Koreans, HLA-B51, DRB1*09,
DQB1*03 and B51-DRB1*09- DQB1*03 haplotype were positively associated with NHL (35).

\section{DRUG-INDUCED ADVERSE EFFECTS (Table V)}

\section{Carbamazepine-induced Severe Cutaneous Adverse Reactions (SCARs)}

Carbamazepine (CBZ), which is widely used to treat seizure disorders, bipolar disorder, trigeminal neuralgia, and chronic pain, is one of most common causes of drug hypersensitivity reactions. It occasionally causes a severe cutaneous adverse reactions (SCARs), such as hypersensitivity syndrome (HSS), Stevens-Johnson syndrome (SJS), and toxic epidermal necrolysis (TEN). The US FDA recommends screening for HLA-B*1502 allele in most of Asian ancestry before initiating carbamazepine therapy. In this background, recent result in Korean population showed that the frequencies of $A^{*} 3101$ in CBZ-induced HSS/SCARs were significantly higher than those in CBZ-tolerant controls (35). The frequencies of $A * 3101$ in CBZ-induced HSS/SCARs and B*1511 in carbamazepine-induced SJS were significantly higher than those in the general population (36).

\section{Methazolamide-induced SJS \& TEN}

The carbonic anhydrase inhibitor methazolamide infrequently causes Stevens- Johnson syndrome (SJS) and toxic epidermal necrolsis (TEN). An association between these diseases and

Table V. Drug-induced adverse effects positively associated with HLA alleles in Korean population

\begin{tabular}{lrrr}
\hline \multicolumn{1}{c}{ Disease } & $\begin{array}{c}\text { Odds } \\
\text { ratio }\end{array}$ & p-value & Ref. \\
\hline Carbamazepine-induced & & & \\
Severe cutaneous adverse reactions & (SCARs) & & \\
A*3101 & 7.6 & 0.013 & $(36)$ \\
A*3101 (Hypersensitivity & 8.8 & 0.011 & $(36)$ \\
$\quad$ syndrome, HSS) & & & \\
B*1511 (Stevens-Johnson & 18.0 & 0.011 & \\
syndrome, SJS) & & & \\
Methazolamide-induced Stevens-Johnson syndrome (SJS) \\
\& Toxic epidermal necrolysis (TEN) \\
B*5901 \\
Cw*0102 \\
Allopurinol-induced SCARs & 249.8 & $<0.001$ \\
A*3303 & 22.1 & 0.004 \\
B*5801 & 20.5 & $3.31 * 10^{-6}$ & \\
Cw*0302 & 97.8 & $2.45^{*} 10^{-11}$ & $(38)$ \\
\hline
\end{tabular}


Table VI. Miscellaneous diseases positively associated with HLA alleles in Korean population

\begin{tabular}{|c|c|c|c|}
\hline Disease & $\begin{array}{l}\text { Odds } \\
\text { ratio }\end{array}$ & p-value & Ref. \\
\hline \multicolumn{4}{|c|}{$\begin{array}{l}\text { Non-responsive group to corticosteroid therapy in patients with } \\
\text { sudden hearing loss }\end{array}$} \\
\hline $\mathrm{DRB} 1 * 04$ & 3.0 & 0.046 & (39) \\
\hline DRB1*14 & 3.5 & $<0.02$ & (40) \\
\hline DQA $1 * 03$ & 4.2 & $<0.02$ & (40) \\
\hline DQA $1 * 05$ & 3.1 & $<0.03$ & (40) \\
\hline DQA $1 * 03$ and 05 (co-existence) & 8.9 & $<0.001$ & (40) \\
\hline \multicolumn{4}{|l|}{ Meniere's disease } \\
\hline $\mathrm{Cw}^{*} 0303$ & 2.5 & $<0.02$ & (41) \\
\hline $\mathrm{Cw}^{*} 0602$ & 3.7 & $<0.03$ & (41) \\
\hline B13 (with hearing loss) & 7.4 & $<0.004$ & (41) \\
\hline B39 (with hearing loss) & 45.7 & $<0.003$ & (41) \\
\hline $\mathrm{Cw}^{*} 0303$ (with hearing loss) & 4.5 & $<0.02$ & (41) \\
\hline $\mathrm{Cw}^{*} 0602$ (with hearing loss) & 6.5 & $<0.02$ & (41) \\
\hline $\begin{array}{l}\text { DRB } 1 * 0405 \text { (anti-Cll positive } \\
\text { subgroup) }\end{array}$ & 8.51 & 0.006 & $(42)$ \\
\hline $\begin{array}{l}\text { DRB1*1201 (anti-Cll negative } \\
\text { subgroup) }\end{array}$ & 2.61 & 0.03 & $(42)$ \\
\hline \multicolumn{4}{|l|}{ Vogt-Koyanagi-Harada syndrome } \\
\hline $\mathrm{DRB} 1 * 04$ & 45.1 & $<1 * 10^{-7}$ & (43) \\
\hline DQA $1 * 0302$ & 12.0 & $<1 * 10^{-4}$ & (43) \\
\hline DQB1*0401 & 18.9 & $<1 * 10^{-6}$ & (43) \\
\hline \multicolumn{4}{|l|}{ Takayasu arteritis } \\
\hline $\begin{array}{l}\text { B*5201 (congestive heart } \\
\text { failure) }\end{array}$ & 5.94 & $<0.05$ & (44) \\
\hline $\mathrm{Bw}^{*} 52$ & 6.2 & $<0.02$ & (45) \\
\hline $\mathrm{Cw}^{*} 6$ & 4.1 & $<0.05$ & (45) \\
\hline DR7 & 4.5 & $<0.04$ & (45) \\
\hline $\mathrm{DQw}^{*} 2$ & 7.3 & $<0.01$ & (45) \\
\hline \multicolumn{4}{|l|}{ Kawasaki disease } \\
\hline B35 & 3.1 & $<0.006$ & (46) \\
\hline B75 & 8.2 & $<0.02$ & (46) \\
\hline $\mathrm{Cw}^{*} 09$ & 2.0 & $<0.04$ & (46) \\
\hline $\begin{array}{l}\text { DRB } 1 * 11 \text { (coronary artery } \\
\text { complication) }\end{array}$ & 4.7 & $<0.04$ & (46) \\
\hline \multicolumn{4}{|l|}{ Moyamoya disease } \\
\hline B35 & 4.2 & $<0.008$ & $(47)$ \\
\hline \multicolumn{4}{|c|}{ Idiopathic pulmonary arterial hypertension } \\
\hline $\mathrm{DRB} 1 * 0406$ & 3.09 & 0.004 & (48) \\
\hline DQB1*0302 & 2.03 & 0.034 & (48) \\
\hline DRB1*0406-DQB1*0302 & 3.54 & 0.0006 & (48) \\
\hline \multicolumn{4}{|l|}{ Diffuse panbronchiolitis } \\
\hline A11 & 5.4 & $1.2 * 10^{-4}$ & (49) \\
\hline B55 & 5.5 & 0.05 & (49) \\
\hline
\end{tabular}

Table VI. continued

\begin{tabular}{|c|c|c|c|}
\hline Disease & $\begin{array}{l}\text { Odds } \\
\text { ratio }\end{array}$ & p-value & Ref. \\
\hline \multicolumn{4}{|l|}{ Ulcerative colitis } \\
\hline DR2 & 2.11 & 0.001 & $(50)$ \\
\hline $\mathrm{DRB} 1 * 1502$ & 3.9 & 0.0005 & $(50)$ \\
\hline \multicolumn{4}{|l|}{ Polycystic ovarian syndrome } \\
\hline A11 & 2.79 & 0.032 & $(51)$ \\
\hline A31 & 6.05 & 0.019 & $(51)$ \\
\hline B54 & 6.40 & 0.002 & $(51)$ \\
\hline \multicolumn{4}{|l|}{ Endometriosis } \\
\hline B39 & & NS & $(52)$ \\
\hline DRB1 & & NS & $(53)$ \\
\hline \multicolumn{4}{|c|}{ Responder to immunosuppressive therapy in aplastic anemia } \\
\hline DR15 & 24.8 & $=0.0002$ & (54) \\
\hline \multicolumn{4}{|l|}{ Bipolar disorder } \\
\hline A29 & 5.91 & $=0.014$ & (55) \\
\hline B54 & 1.97 & $=0.035$ & (55) \\
\hline \multicolumn{4}{|l|}{ Narcolepsy } \\
\hline DRB $1 * 1501$ & 583.96 & $=2.3 * 10^{-30}$ & $(57)$ \\
\hline $\begin{array}{l}\text { DQB } 1 * 0602 \text { (with typical } \\
\text { cataplexy) }\end{array}$ & 90.52 & $<0.0001$ & (56) \\
\hline $\mathrm{DQB} 1 * 0602$ & 605.00 & $=3.9 * 10^{-31}$ & (57) \\
\hline
\end{tabular}

NS: not significant.

the HLA-B59 serotype has been suggested in case reports. In a study aimed to investigate disease-associated B59 and other HLA class I alleles, the frequencies of B*5901 and $\mathrm{CW}^{*} 0102$ were very significantly increased with methazolamide-induced SJS \& TEN (37).

\section{Allopurinol-induced SCARs}

Allopurinol is a drug used primarily to treat hyperuricemia and its complications, including chronic gout. Recent investigations suggest genetic susceptibility of allopurinol-induced severe cutaneous adverse reactions (SCARs). However, the strength of association was variable according to phenotypes and ethnic backgrounds. The frequencies of HLA-A*3303, $\mathrm{B}^{* 5801}$ and $\mathrm{CW}^{*} 0302$ were significantly higher in allopurinol-induced SCARs compared with tolerant controls (38).

\section{MISCELLANEOUS DISEASES (Table VI)}

\section{Sudden Hearing Loss}

Sudden sensorineural hearing loss (SNHL) is a partial or complete, typically unilateral hearing loss characterized by a rapidity of onset or a progression that may occur within a few 
moments or for a few days. Sudden SNHL has numerous possible causes, including viral infection, vascular occlusion, cochlear membrane breaks, ototoxic drugs, and bacterial infection. Autoimmunity or immunologic disorders have been suggested as possible causes of idiopathic progressive SNHL; however, the role of genetic factors in the pathogenesis has not been studied. In two studies aimed to define the association of HLA class II alleles with the susceptibility to SNHL and with the results of corticosteroid treatment, the frequencies of HLA-DRB1*04, DRB1*14, DQA1*03 and DQA1*05 were significantly increased but, those of DQA1*01 and DQB1*06 were significantly decreased in the group nonresponsive to corticosteroid therapy, compared with the controls $(39,40)$. The co-existence of DQA1*03 and DQA1*05 had highest frequency in this nonresponsive group (39).

\section{Meniere's Disease (MD)}

There have been succeeding reports concerning the autoimmunity and circulating immune complexes involved in the pathogenesis of MD. Several autoantigens have been suggested in the pathogenesis of autoimmune inner ear diseases, one being type 2 collagen (CII). Elevated levels of anti-CII antibodies have been documented in patients with MD. As to the pathogenesis of the disease, MD patients occasionally have a positive family history, suggesting some genetic predisposing factors involved in the disease. A few studies have shown HLA associations with MD and other autoimmune inner ear diseases with variable results. HLA-A1, B8, Cw7 or DR4 were increased in Caucasian patients and DR2 (DRB1*1602) was increased in Japanese patients with MD. In Koreans, two studies aimed to investigate HLA-associated genetic susceptibility to MD in relation to CII showed that the frequencies of $\mathrm{Cw}^{*} 0303$ and $\mathrm{Cw}^{*} 0602$ were significantly increased and the frequencies of $\mathrm{B} 44, \mathrm{Cw}^{*} 0102$ were significantly decreased compared to controls (41). When the association between hearing level and the presence of particular HLA alleles was evaluated, the frequencies of B13, B39, $\mathrm{CW}^{*} 0303$ and $\mathrm{CW}^{*} 0602$ were significantly increased and those of B44 and C*0102 were significantly decreased in MD patients with hearing losses (stages II-IV) (41). In the anti-CII positive subgroup of $\mathrm{MD}$ patients, the frequency of DRB1*0405 was significantly increased and in the anti-CII negative patients, DRB1*1201 was increased and DRB1*13 was decreased compared to controls (42).

\section{Vogt-Koyanagi-Harada (VKH) Syndrome}

VKH syndrome is a systemic disorder characterized by depigmentary inflammation of melanocyte-containing tissues and usually causes bilateral diffuse granulomatous uveitis, alopecia, vitiligo, poliosis, tinnitus, dysacousia, and meningeal symptoms. The exact cause of the syndrome is uncertain, but the roles of autoimmune mechanisms in the pathogenesis of the syndrome have been well known. One of the important characteristics of the disease is its association with HLA. The association of HLA-DR1, DR4, DR53, DQ4 antigens and DRB1*04, DQA1, DQB1 subtypes with VKH syndrome has been documented in Japanese, Brazilian, Hispanic, and Chinese patients. HLA typing was performed in 18 Korean patients with VKH syndrome (43). The frequencies of A31, B55, DRB1*0405, DQA1*0302, DQB1*0401 and DPB1*0501 were significantly increased in the patients group compared with the control group. DRB1*04 showed strongest association with VKH syndrome (43).

\section{Takayasu Arteritis (TA)}

TA occurs with a strong predilection for women and particular geographic areas, and as related to the etiology of the disease, association of HLA antigens has been suggested. Two studies showed that the frequencies of HLA-A*3001,

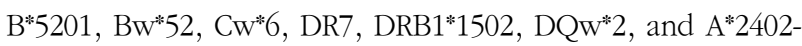
B*5201-DRB1*1502 haplotype were significantly higher in TA patients and the frequency of $A * 2602$ was significantly lower in TA patients compared with controls $(44,45)$. Further, among the serious complication of TA, congestive heart failure was found to be positively associated with B*5201 (44).

\section{Kawasaki Disease}

Kawasaki disease is a leading cause of acquired heart disease in children. The prevalence rate varies in different ethnic groups. In a study aimed to assess the association of HLA alleles with susceptibility and complications of Kawasaki disease in Korean children, there was a significant increase in the frequencies of the HLA-B35, B75 and $\mathrm{CW}^{*} 09$ alleles in patients with Kawasaki disease compared with the healthy control group. And Kawasaki disease patients with coronary artery complications showed a significantly increased frequency of DRB1*11 (46).

Moyamoya Disease. Moyamoya disease is characterized by progressive cerebrovascular occlusion at the peripheral internal carotid artery and development of abnormal collateral circulation at the cerebral basal region. Although abnormal thrombogenesis, inflammation and autoimmune process might be involved in the etiology, the genetic pathogenesis of Moyamoya disease is still unknown. The frequency of HLA-B35 allele was significantly increased in the patients compared to the controls (47). 


\section{Idiopathic Pulmonary Arterial Hypertension (IPAH)}

$\mathrm{PAH}$ is a clinically heterogeneous entity, which is associated with immune system dysfunction, including autoimmune diseases and HIV infection. IPAH is a rare disease in which consistently increased pulmonary arterial pressure and pulmonary vascular resistance of unknown cause lead to right heart failure and death. Alterations in the frequency of HLA class II alleles usually accompany autoimmune diseases. Increases in the frequency of the HLA-DR3, DRw52, and DQw2 alleles have been detected in children with IPAH. In addition, DRw52 was found to be more common in adult patients with pulmonary hypertension and scleroderma than in controls and the frequency of DQ7 was elevated in both adult and adolescent patients with IPAH. The frequency of DRB1 and DQB1 alleles in Korean patients with IPAH was studied to determine any association that may exist between clinical characteristics of IPAH and specific HLA alleles. The patients with IPAH had a significantly higher frequency of the DRB1*0406, DQB1* 0302, and DRB1*0406-DQB1*0302 haplotype (48).

\section{Diffuse Panbronchiolitis (DPB)}

DPB is a chronic obstructive pulmonary disease of unknown etiology. Observations of significantly increased frequency of HLA-B54 in Japanese patients and occurrence of familial cases suggest possible genetic predisposition to the disease susceptibility. In Koreans, the frequencies of A11 and B55 were significantly increased with DPB (49).

\section{Ulcerative colitis (UC)}

$\mathrm{UC}$ is a form of inflammatory bowel disease (IBD). Although dietary modification may reduce the discomfort of a person with the disease, ulcerative colitis is not thought to be caused by dietary factors. Ulcerative colitis is treated as an autoimmune disease. Several studies have documented the high incidence of several HLA class II alleles in Japanese patients with UC. In Korean population, a study showed that HLA-DR2 and DRB1*1502 were found more frequently in patients than controls (50).

\section{Polycystic Ovarian Syndrome (PCOS)}

PCOS is one of the most common female endocrine disorders and is a complex, heterogeneous disorder of uncertain etiology. But, there is strong evidence that it can to a large degree be classified as a genetic disease. Although several studies have demonstrated the genetic contribution to PCOS, the cause of this syndrome remains unclear. In a study aimed to elucidate the relationship between HLA systems and PCOS in Koreans and to investigate the association of HLA with free-testosterone level, HLA-A11, A31 and B54 were positively associated with phenotype frequencies in PCOS women compared to controls (51).

\section{Endometriosis}

Endometriosis is defined as the presence of endometrial tissue outside the uterus, causing diverse diseases, including infertility, pelvic pain, dysmenorrhea, and constipation. While there is a growing body of evidence that genetic and immunologic factors play important roles in the pathogenesis of the disease, HLA have been reported to be associated with the risk of endometriosis in the Japanese population. The findings of the two studies in Koreans suggested that the susceptibility to endometriosis, unlike in the Japanese population, is not associated with HLA-A, B and DRB1 antigens in the Korean population $(52,53)$.

\section{Aplastic Anemia (AA)}

AA is a condition where bone marrow does not produce sufficient new cells to replenish blood cells. In many cases, the etiology is considered to be unknown but one known cause is an autoimmune disorder in which white blood cells attack the bone marrow. Also, HLA-DR15 is overrepresented in aplastic anemia patients, and its presence is associated with a better response to cyclosporine-based immunosuppressive therapy. However, little is known about other HLA alleles affecting therapy response. In this situation, a recent study in Koreans showed that in responders, the frequency of DR4 was significantly lower and that of DR 15 was significantly higher than in nonresponders (54).

\section{Bipolar disorder}

Many studies have been dedicated to determining the genetic predispositions for bipolar disorder and the possible candidate genes for this disorder have been presumed to be located in three specific chromosome regions: (i) the end of short arm of chromosome 11; (ii) the long arm of the X chromosome; and (iii) HLA complex on chromosome 6. Of these three candidates, HLA has drawn major interest as a biological marker for bipolar disorder, which has led to a rapid expansion in the number of investigations into the association of HLA with bipolar disorder. However, previous reports on the association of HLA with bipolar disorder have been inconsistent. In a study aimed to elucidate an association between HLA alleles and bipolar disorder, the potentiality of HLA was evaluated as a genetic marker in bipolar disorder. Bipolar patients showed statistically significantly increased allele frequencies of HLA-A29 and B54 and decreased allele frequencies of B51 and DRB1*02 (55). 


\section{Narcolepsy}

The sleep disorder narcolepsy is characterized by excessive daytime sleepiness, cataplexy (sudden episodes of loss of muscle tone triggered by emotions), and rapid transitions into rapid eye movement sleep. Recent studies have shown that the human disorder is caused by the destruction of most of approximately 70,000 hypothalamic neurons that secrete a wake-promoting neuropeptide called hypocretin. Measuring hypocretin-1 in the cerebrospinal fluid of patients is now an accepted diagnostic test, with low levels indicating narcolepsy. Based on the observations of the HLA association in the disorder, an autoimmune-mediated destruction of hypocretin-containing cells has been proposed as the cause of most human cases. The association of narcolepsy with HLADQB1*0602 is established in Japanese, African-Americans, European, and North American Caucasians. Also, HLA-DRB1, DRB3, DRB4, DRB5, DQA1, and DQB1 in Korean population showed significantly increased frequency of DRB1*1501, DQB1*0602 and decreased frequency of DQB1*0601 $(56,57)$.

\section{CONCLUSIONS}

Genetic and genomic analysis of complex diseases will play an important role in identification of new molecular targets for intervention with pharmaceutical and biological drugs. They would be helpful in prediction of the likely effectiveness of particular therapies according to genotypes of individuals. The HLA associations are clinically used for diagnosis, prognosis and prophylaxis in a few of the diseases and some association studies provided to clarify disease heterogeneity (1). However, we could also find the different HLA association data according to population in some diseases. Several environmental factors explain at least part of the excess risk and differences in genetic constitution could affect disease susceptibility. There is a need to create larger databases, including cohorts in Korean population in addition to different ethnicities, more rigorous molecular typing, excellent longitudinal data, appropriate statistical analysis and plausible biological associations. Immunogenetic profiling of patients with large genetic variations including HLA is likely to realize the personalized medicine in future (58).

\section{ACKNOWLEDGEMENTS}

This study was supported by a grant from the CRCID (Convergent Research Consortium for Immunologic Disease), Ministry for Health and Welfare, Republic of Korea.

\section{CONFLICTS OF INTEREST}

The author have no financial conflict of interest.

\section{REFERENCES}

1. Ghodke Y, Joshi K, Chopra A, Patwardhan B: HLA and disease. Eur J Epidemiol 20;475-88, 2005.

2. Shiina T, Inoko H, Kulski JK: An update of the HLA genomic region, locus information and disease associations: 2004. Tissue Antigens 64;631-649, 2004.

3. Nepom GT: Class II antigens and disease susceptibility. Annu Rev Med 46;17-25, 1995.

4. Ota M, Katsuyama Y, Kimura A, Tsuchiya K, Kondo M, Naruse T, Mizuki N, Itoh K, Sasazuki T, Inoko H: A second susceptibility gene for developing rheumatoid arthritis in the human MHC is localized within a 70-kb interval telomeric of the TNF genes in the HLA class III region. Genomics 71;263-270, 2001.

5. The International HIV Controllers Study: the major genetic determinants of HIV-1 control affect HLA class I peptide presentation. Science 330;1488-1490, 2010.

6. Nepom GT: MHC genes in HLA-associated disease. Curr Opin Immunol 2;588-592, 1989-1990.

7. Kim TG, Choi HB, Park SH, Kim HY, Han H: DQCAR 113 and DQCAR 115 in combination with HLA-DRB1 alleles are significant markers of susceptibility to rheumatoid arthritis in the Korean population. Tissue Antigens 54;552-559, 1999.

8. Hong GH, Park MH, Takeuchi F, Oh MD, Song YW, Nabeta $\mathrm{H}$, Nakano K, Ito K, Park KS: Association of specific amino acid sequence of HLA-DR with rheumatoid arthritis in Koreans and its diagnostic value. J Rheumatol 23;1699-1703, 1996.

9. Kim HY, Kim TG, Park SH, Lee SH, Cho CS, Han H: Predominance of HLA-DRB1*0405 in Korean patients with rheumatoid arthritis. Ann Rheum Dis 54;988-990, 1995.

10. Lee HS, Chung YH, Kim TG, Kim TH, Jun JB, Jung S, Bae SC, Yoo DH: Independent association of HLA-DR and FCgamma receptor polymorphisms in Korean patients with systemic lupus erythematosus. Rheumatology (Oxford) 42; 1501-1507, 2003.

11. Hong GH, Kim HY, Takeuchi F, Nakano K, Yamada H, Matsuta K, Han H, Tokunaga K, Ito K, Park KS: Association of complement C4 and HLA-DR alleles with systemic lupus erythematosus in Koreans. J Rheumatol 21;442-447, 1994.

12. Park KS, Kang SY, Lee WI: HLA-B27 subtypes in Korean patients with ankylosing spondylitis. Korean J Lab Med 28;46-52, 2008.

13. Joung CI, Lee HS, Lee SW, Kim CG, Song YH, Jun JB, Chung WT, Choe JY, Kim TG, Yoo DH: Association between HLA-DR B1 and clinical features of adult onset Still's disease in Korea. Clin Exp Rheumatol 21;489-492, 2003.

14. Kang SH, Park MH, Song EY, Kang SJ, Lee EB, Song YW, 
Takeuchi F: Association of HLA class II genes with systemic sclerosis in Koreans. J Rheumatol 28;1577-1583, 2001.

15. Zhou X, Lee JE, Arnett FC, Xiong M, Park MY, Yoo YK, Shin ES, Reveille JD, Mayes MD, Kim JH, Song R, Choi JY, Park JA, Lee YJ, Lee EY, Song YW, Lee EB: HLA-DPB1 and DPB2 are genetic loci for systemic sclerosis: a genome-wide association study in Koreans with replication in North Americans. Arthritis Rheum 60;3807-3814, 2009.

16. Park SH, Park KS, Seo YI, Min DJ, Kim WU, Kim TG, Cho CS, Mok JW, Park KS, Kim HY: Association of MICA polymorphism with HLA-B51 and disease severity in Korean patients with Behcet's disease. J Korean Med Sci 17;366-370, 2002.

17. Cho WK, Jung MH, Choi EJ, Choi HB, Kim TG, Suh BK: Association of HLA Alleles with autoimmune thyroid disease in Korean children. Horm Res Paediatr 76;328-334, 2011.

18. Jang HW, Shin HW, Cho HJ, Kim HK, Lee JI, Kim SW, Kim JW, Chung JH: Identification of HLA-DRB1 alleles associated with Graves' disease in Koreans by sequence-based typing. Immunol Invest 40;172-182, 2011.

19. Park MH, Park YJ, Song EY, Park H, Kim TY, Park DJ, Park KS, Cho BY: Association of HLA-DR and -DQ genes with Graves disease in Koreans. Hum Immunol 66;741-747, 2005.

20. Cho BY, Chung JH, Shong YK, Chang YB, Han H, Lee JB, Lee HK, Koh CS: A strong association between thyrotropin receptor-blocking antibody-positive atrophic autoimmune thyroiditis and HLA-DR8 and HLA-DQB1*0302 in Koreans. J Clin Endocrinol Metab 77;611-615, 1993.

21. Mignot E, Kimura A, Abbal M, Thorsby E, Lin X, Voros A, Macaubas C, Bouissou F, Sollid LM, Cambon-Thomsen A: DQCAR microsatellite polymorphisms in three selected HLA class II-associated diseases. Tissue Antigens 46;299-304, 1995.

22. Park YS, Wang CY, Ko KW, Yang SW, Park M, Yang MC, She JX: Combinations of HLA DR and DQ molecules determine the susceptibility to insulin-dependent diabetes mellitus in Koreans. Hum Immunol 59;794-801, 1998.

23. Kim TG, Lee HJ, Youn JI, Kim TY, Han H: The association of psoriasis with human leukocyte antigens in Korean population and the influence of age of onset and sex. J Invest Dermatol 114;309-313, 2000.

24. Lee HJ, Ha SJ, Han H, Kim JW: Distribution of HLA-A, B alleles and polymorphisms of TAP and LMP genes in Korean patients with atopic dermatitis. Clin Exp Allergy 31;1867-1874, 2001.

25. Kim YK, Oh SY, Oh HB, Lee BJ, Son JW, Cho SH, Kim YY, Min KU: Positive association between HLA-DRB1*07 and specific IgE responses to purified major allergens of D. pteronyssinus (Der p 1 and Der p 2). Ann Allergy Asthma Immunol 88;170-174, 2002.

26. Kim YK, Oh HB, Oh SY, Cho SH, Kim YY, Min KU: HLA-DRB1*07 may have a susceptibility and DRB1*04 a protective effect upon the development of a sensitization to house dust mite Dermatophagoides pteronyssinus. Clin Exp Allergy 31;110-115, 2001.

27. Choi JH, Lee KW, Oh HB, Lee KJ, Suh YJ, Park CS, Park HS: HLA association in aspirin-intolerant asthma: DPB1*
0301 as a strong marker in a Korean population. J Allergy Clin Immunol 113;562-564, 2004.

28. Choi JH, Lee KW, Kim CW, Park CS, Lee HY, Hur GY, Kim SH, Hong CS, Jang AS, Park HS: The HLA DRB1*1501DQB1*0602-DPB1*0501 haplotype is a risk factor for toluene diisocyanate-induced occupational asthma. Int Arch Allergy Immunol 150;156-163, 2009.

29. Hwang SH, Sohn YH, Oh HB, Hwang CY, Lee SH, Shin ES, Lee KJ: Human leukocyte antigen alleles and haplotypes associated with chronicity of hepatitis B virus infection in Koreans. Arch Pathol Lab Med 131;117-121, 2007.

30. Park MH, Song EY, Ahn C, Oh KH, Yang J, Kang SJ, Lee HS: Two subtypes of hepatitis B virus-associated glomerulonephritis are associated with different HLA-DR2 alleles in Koreans. Tissue Antigens 62;505-511, 2003.

31. Yoon SK, Han JY, Pyo CW, Yang JM, Jang JW, Kim CW, Chang UI, Bae SH, Choi JY, Chung KW, Sun HS, Choi HB, Kim TG: Association between human leukocytes antigen alleles and chronic hepatitis $\mathrm{C}$ virus infection in the Korean population. Liver Int 25;1122-1127, 2005.

32. Kim HS, Park MH, Song EY, Park H, Kwon SY, Han SK, Shim YS: Association of HLA-DR and HLA-DQ genes with susceptibility to pulmonary tuberculosis in Koreans: preliminary evidence of associations with drug resistance, disease severity, and disease recurrence. Hum Immunol 66; 1074-1081, 2005.

33. Um SW, Ki CS, Kwon OJ, Koh WJ: HLA antigens and nontuberculous mycobacterial lung disease in Korean patients. Lung 187;136-140, 2009.

34. Lee HW, Hahm KB, Lee JS, Ju YS, Lee KM, Lee KW: Association of the human leukocyte antigen class II alleles with chronic atrophic gastritis and gastric carcinoma in Koreans. J Dig Dis 10;265-271, 2009.

35. Choi HB, Roh SY, Choi EJ, Yoon HY, Kim SY, Hong YS, Kim DW, Kim TG: Association of HLA alleles with non-Hodgkin's lymphoma in Korean population. Int J Hematol 87;203-209, 2008.

36. Kim SH, Lee KW, Song WJ, Kim SH, Jee YK, Lee SM, Kang HR, Park HW, Cho SH, Park SH, Min KU, Chang YS; Adverse Drug Reaction Research Group in Korea: Carbamazepine-induced severe cutaneous adverse reactions and HLA genotypes in Koreans. Epilepsy Res 97;190-197, 2011.

37. Kim SH, Kim M, Lee KW, Kim SH, Kang HR, Park HW, Jee YK: HLA-B*5901 is strongly associated with methazolamide-induced Stevens-Johnson syndrome/toxic epidermal necrolysis. Pharmacogenomics 11;879-884, 2010.

38. Kang HR, Jee YK, Kim YS, Lee CH, Jung JW, Kim SH, Park HW, Chang YS, Jang IJ, Cho SH, Min KU, Kim SH, Lee KW; Adverse Drug Reaction Research Group in Korea: Positive and negative associations of HLA class I alleles with allopurinol-induced SCARs in Koreans. Pharmacogenet Genomics 21;303-307, 2011.

39. Yeo SW, Chang KH, Suh BD, Kim TG, Han H: Distribution of HLA-A, -B and -DRB1 alleles in patients with sudden sensorineural hearing loss. Acta Otolaryngol 120;710-715, 2000.

40. Yeo SW, Park SN, Park YS, Suh BD, Han H, Choi HB, Kim TG: Different distribution of HLA class II alleles according 
to response to corticosteroid therapy in sudden sensorineural hearing loss. Arch Otolaryngol Head Neck Surg 127;945-949, 2001

41. Yeo SW, Park SN, Jeon EJ, Lee HY, Pyo CW, Kim TG: Influence of human leukocyte antigen in the pathogenesis of Ménière's disease in the South Korean population. Acta Otolaryngol 122;851-856, 2002.

42. Koo JW, Oh SH, Chang SO, Park MH, Lim MJ, Yoo TJ, Kim CS: Association of HLA-DR and type II collagen autoimmunity with Meniere's disease. Tissue Antigens 61;99103, 2003.

43. Kim MH, Seong MC, Kwak NH, Yoo JS, Huh W, Kim TG, Han H: Association of HLA with Vogt-Koyanagi-Harada syndrome in Koreans. Am J Ophthalmol 129;173-177, 2000.

44. Lee SW, Kwon OJ, Park MC, Oh HB, Park YB, Lee SK: HLA alleles in Korean patients with Takayasu arteritis. Clin Exp Rheumatol 25(1 Suppl 44);S18-S22, 2007.

45. Park MH, Park YB: HLA typing of Takayasu arteritis in Korea. Heart Vessels Suppl 7;81-84, 1992.

46. Oh JH, Han JW, Lee SJ, Lee KY, Suh BK, Koh DK, Lee JS, Oh CK, Kim TG, Choi HB: Polymorphisms of human leukocyte antigen genes in korean children with Kawasaki disease. Pediatr Cardiol 29;402-408, 2008.

47. Han H, Pyo CW, Yoo DS, Huh PW, Cho KS, Kim DS: Associations of Moyamoya patients with HLA class I and class II alleles in the Korean population. J Korean Med Sci 18;876-880, 2003.

48. Yoon SH, Oh HB, Kim HK, Hong SC, Oh YM, Lee DS, Lee SD: Association of HLA class II genes with idiopathic pulmonary arterial hypertension in Koreans. Lung 185;145-149, 2007.

49. Park MH, Kim YW, Yoon HI, Yoo CG, Han SK, Shim YS, Kim WD: Association of HLA class I antigens with diffuse panbronchiolitis in Korean patients. Am J Respir Crit Care Med 159;526-529, 1999.

50. Myung SJ, Yang SK, Jung HY, Chang HS, Park B, Hong
WS, Kim JH, Min I: HLA-DRB1*1502 confers susceptibility to ulcerative colitis, but is negatively associated with its intractability: a Korean study. Int J Colorectal Dis 17;233-237, 2002.

51. Kim JJ, Hwang KR, Shin S, Yoon JH, Kim BJ, Choi YM, Roh EY: Association of polycystic ovarian syndrome with human leukocyte antigen polymorphism in Korean women. APMIS 119;618-625, 2011.

52. Whang DH, Kim SH, Park MH, Choi YM: Association of HLA-A, B antigens with susceptibility to advanced endometriosis in Koreans. Korean J Lab Med 28;118-123, 2008.

53. Whang DH, Kim SH, Choi YM, Park MH, Noh JH, Kim YB: No association between HLA-DRB1 alleles and susceptibility to advanced stage endometriosis in a Korean population. Hum Reprod 21;129-133, 2006.

54. Song EY, Kang HJ, Shin HY, Ahn HS, Kim I, Yoon SS, Park S, Kim BK, Park MH: Association of human leukocyte antigen class II alleles with response to immunosuppressive therapy in Korean aplastic anemia patients. Hum Immunol 71;88-92, 2010.

55. Jun TY, Pae CU, Chae JH, Pyo CW, Han H: Human leukocyte antigen alleles in patients with bipolar disorder in the Korean population. Psychiatry Clin Neurosci 56;453-457, 2002.

56. Hong SC, Lin L, Lo B, Jeong JH, Shin YK, Kim SY, Kweon Y, Zhang J, Einen M, Smith A, Hansen J, Grumet FC, Mignot E: DQB1*0301 and DQB1*0601 modulate narcolepsy susceptibility in Koreans. Hum Immunol 68;59-68, 2007.

57. Roh EY, Park MH, Park H, Park DH, Choi JB, Kim SJ, Jeong DU: Association of HLA-DR and -DQ genes with narcolepsy in Koreans: comparison with two control groups, randomly selected subjects and DRB1*1501-DQB1*0602--positive subjects. Hum Immunol 67;749-755, 2006.

58. Hill AV: Immunogenetics and genomics. Lancet 357;20372041, 2001. 